Brit. J. industr. Med., 1962, 19, 171.

\title{
CORRELATION OF RADIOLOGICAL CATEGORY WITH LUNG PATHOLOGY IN COAL-WORKERS' PNEUMOCONIOSIS
}

\author{
BY \\ ANTHONY CAPLAN \\ Pneumoconiosis Medical Panel, Cardiff \\ (RECEIVED FOR PUBLICATION OCTOBER 20, 1961)
}

\begin{abstract}
The relation between the macroscopic pathology of the lungs of coal-workers and the radiological category of pneumoconiosis on a chest film taken not more than two years before death has been investigated in 238 coal-miners in South Wales. Large lung sections were shown to provide more accurate and convenient material than wet lungs for this comparison and were used to assess the number and character of dust foci and the degree of emphysema. The profusion of dust foci was classified into four grades-very sparse, sparse, moderate, and numerous-using standard lung sections. Emphysema was graded slight, moderate, and severe. The chest radiographs were categorized according to the I.L.O. Classification, 1953.

The comparison shows that there is a fairly good correlation between the radiological category and the number and character of dust foci in the lungs at necropsy. The higher the radiological category the greater the likelihood that the lungs will show a large number of dust foci and particularly a higher proportion of fibrotic nodules, and vice versa. Only about $10 \%$ of the films read as category 1 showed sparse fibrotic nodules on the lung section, and none showed more than this. Fibrotic nodules occurred more frequently when early complicated pneumoconiosis (category A) was also present. There was no evidence that emphysema was obscuring the recognition of the severity of simple pneumoconiosis on the radiograph. The commonest cause of localized areas of consolidation detected radiologically was progressive massive fibrosis; less commonly, apical scars. Other causes were lung cancer, bronchiectasis, and interstitial fibrosis.
\end{abstract}

There is evidence that the radiological category in simple pneumoconiosis is related to the intensity of dust exposure and the quantity of dust retained in the lungs (Roach, 1953). Gough, James, and Wentworth (1949) made a side-by-side comparison of lung sections and radiographs in 76 cases of simple pneumoconiosis and concluded that there was fairly good correspondence between the number of opacities seen in the radiographs and the number of coal nodules found in the lungs. Rivers, Wise, King, and Nagelschmidt (1960) studied the radiological appearances within two years of death of 45 cases of simple pneumoconiosis in coal-workers and the lungs subsequently obtained at necropsy. Their main object was to determine quantitatively the relationship of radiological and pathological features to both the total amount and the composition of dust in the lungs. They found a clear increase in the average weight of total dust with increasing radiological category. The mineral and carbon contributed about equally to the radiological changes, but, weight for weight, mineral contributed about nine times more than carbon, and there was very little mineral.

Each year the Cardiff Pneumoconiosis Medical Panel examines lungs from about 1,000 coal-workers and in many cases chest radiographs are available. Some of this material from necropsies carried out in 1951-1954 has been used to study the correlation of the radiological category of simple pneumoconiosis in coal-workers during life and the number and character of dust foci found in their lungs at death.

\section{Source of Material}

The investigation was confined to post-mortem material prepared at the Welsh National School of Medicine, Cardiff, which supplied the Panel with 


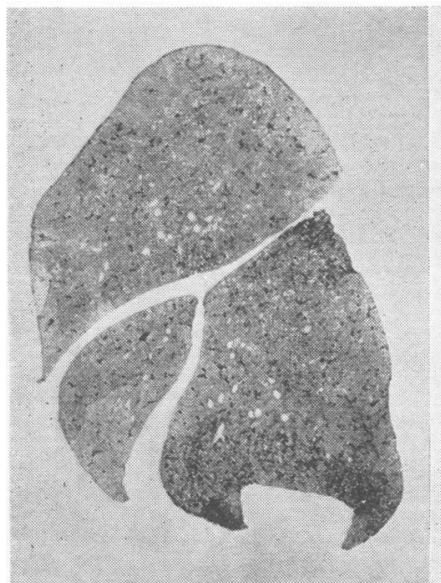

FIG. 1.-Upper limit of very sparse dust foci.

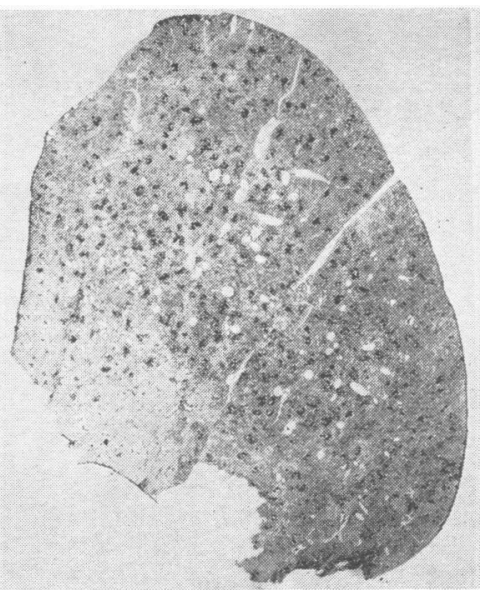

FIG. 2.-Upper limit of sparse dust foci.

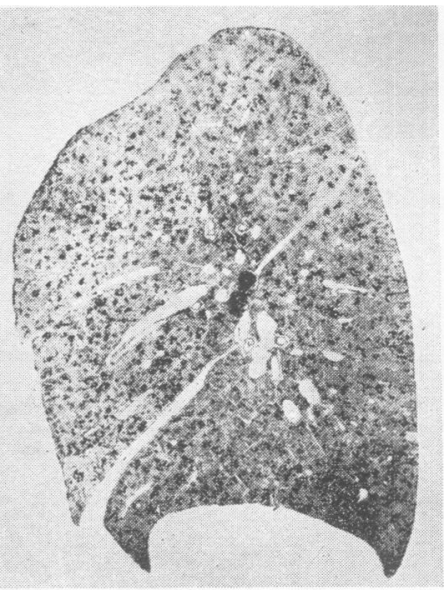

Fig. 3.-Lower limit of numerous dust foci. about $50 \%$ of its material. It is customary at the Pathology Department of the Welsh National School of Medicine to perfuse one of the pair of lungs with formalin and sodium acetate solution as a preliminary to the preparation of large lung sections mounted on paper (Gough et al., 1949). The lungs were seen one to seven days after the date of the post-mortem. Solely on the basis of having available a chest radiograph taken within two years of death and a large lung section prepared by the Gough-Wentworth techniques, 238 cases were selected. Cases of active pulmonary tuberculosis and the more advanced radiological stages of massive pneumoconiosis (B and $\mathbf{C}$ shadows) were excluded because in radiographs of these cases the background of simple pneumoconiosis is often obscured and may be difficult to assess. The 238 cases included 168 with simple pneumoconiosis alone and 62 with early complicated pneumoconiosis (A shadows).

\section{Method}

The pathological assessment of the total number of dust foci both in the wet lung and large lung sections was made by comparing the number of dust foci with three standard lung sections, showing the upper limit of very sparse (Fig. 1), the upper limit of sparse (Fig. 2), and the lower limit of numerous dust foci (Fig. 3). These last two sections were similar to those selected by W. R. L. James (personal communication, 1961) to permit a better appraisal of the profusion of dust foci than by individual subjective assessment on separate occasions. On this basis the total number of dust foci was recorded as "very sparse", "sparse", "moderate", or "numerous". An assessment of the relative number of fibrotic dust foci was also made. Fibrotic nodules, commonly 2 to $10 \mathrm{~mm}$. in diameter, are palpable and characteristically show collagenous fibrosis histologically. The number of fibrotic nodules was recorded as being "none or occasional", "sparse", "moderate", and "numerous", based upon the standard sections used in assessing the total number of dust foci.

The size of the massive fibrosis lesions was measured. Nodular lesions 1.0 to $2.5 \mathrm{~cm}$. were classified as large fibrotic nodules, and lesions greater than $2.5 \mathrm{~cm}$. as progressive massive fibrosis (P.M.F.). The presence of apical scars and other lung abnormalities was also recorded. Emphysema was graded as "none" or "slight", "moderate", and "severe", based broadly on the standards suggested at a Ciba Guest Symposium (1959), and no attempt was made to separate focal, centrilobular, and panlobular varieties.

After preliminary studies had been made it was debated whether or not the large lung section would provide more accurate and convenient material than the wet lung for correlating radiological and postmortem findings. The points in favour of the large lung section were:

(1) The section was permanent and could be examined and re-examined at will, whereas only one record of the readings of the wet lung was available, and it was therefore impossible to test the repeatability of the readings of the wet lung.

(2) The majority of the wet lungs were examined and the findings recorded by two independent observers. About 5\% were examined and recorded by one or other of three independent observers. This introduced the problem of inter-observer variation which could be excluded by one observer reading the large lung sections. 
TABLE 1

COMPARISON OF NUMBER OF DUST FOCI READ IN LARGE LUNG SECTION AND WET LUNG IN 238 CASES

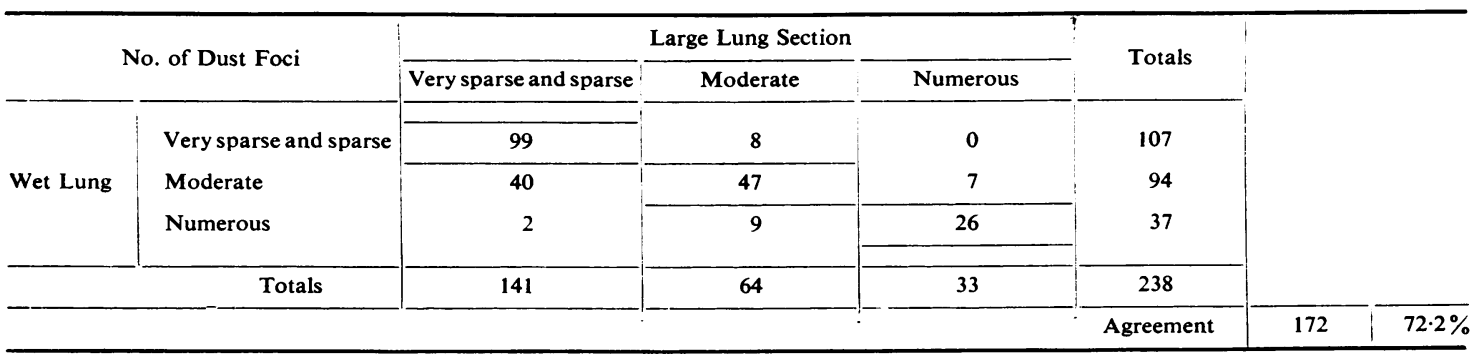

TABLE 2

COMPARISON OF NUMBER OF FIBROTIC DUST FOCI READ IN LARGE LUNG SECTION AND WET LUNG IN 238 CASES

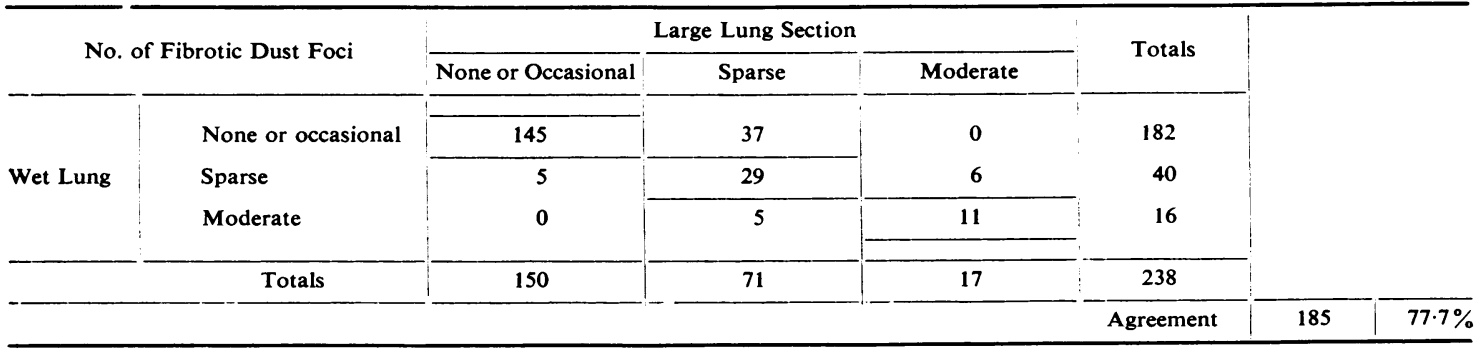

TABLE 3

COMPARISON OF DEGREE OF EMPHYSEMA READ IN LARGE LUNG SECTION AND WET LUNG IN 238 CASES

\begin{tabular}{|c|c|c|c|c|c|c|c|}
\hline \multirow{2}{*}{\multicolumn{2}{|c|}{ Degree of Emphysema }} & \multicolumn{3}{|c|}{ Large Lung Section } & \multirow{2}{*}{ Totals } & & \\
\hline & & None or Slight & Moderate & Severe & & & \\
\hline \multirow{4}{*}{ Wet Lung } & None or slight & 68 & 28 & 4 & \multirow{3}{*}{$\begin{array}{r}100 \\
50 \\
88\end{array}$} & & \\
\hline & Moderate & 9 & 28 & 13 & & & \\
\hline & Sparse & 4 & 24 & 60 & & & \\
\hline & \multirow[t]{2}{*}{ Totals } & 81 & 80 & 77 & 238 & & \\
\hline & & & & & Agreement & 156 & $65.5 \%$ \\
\hline
\end{tabular}

(3) The clinical records and chest radiographs were available and usually examined at the time the wet lungs were examined, and it was impossible to exclude observer bias when recording the postmortem appearances.

(4) The large lung section enabled an experienced observer to identify with greater accuracy the profusion and character of dust foci and the degree of emphysema.

The main point against the use of large lung sections was that being a thin section, it would not be representative of the whole lung. It is certainly true that one cut in a lung may well miss a localized area of disease such as an area of massive fibrosis or cancer, but personal experience over many years has shown that when a disseminated lesion such as coal-workers' simple pneumoconiosis is present the large section cut sagittally fairly accurately represents the appearances throughout the whole lung.

A comparison was made of the readings of the total number of dust foci, fibrotic nodules, and degree of emphysema in the wet lungs and large lung sections. The results are shown in Tables 1,2 , and 3. In assessing the total number of dust foci (Table 1) there was agreement in about $72 \%$ of cases. There was a tendency to read more wet lungs as having moderate dust foci, and fewer with sparse dust foci. In assessing numerous dust foci, there 
TABLE 4

COMPARISON OF FIRST AND SECOND READINGS OF RADIOLOGICAL CATEGORIES IN 238 CASES

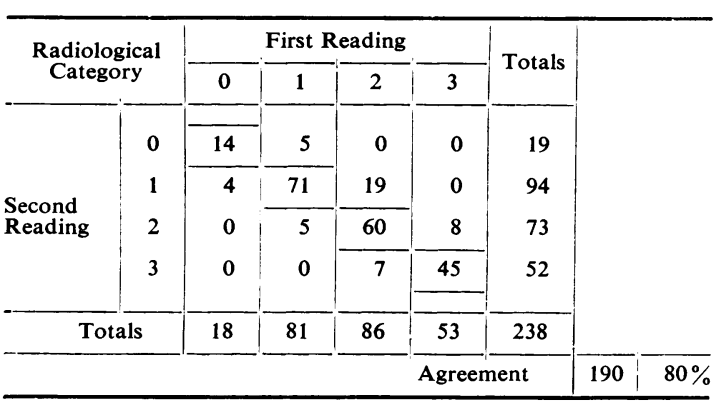

TABLE 8

AGE AND RADIOLOGICAL CATEGORY

\begin{tabular}{|c|c|c|c|c|c|}
\hline \multirow{2}{*}{ Age (years) } & \multicolumn{5}{|c|}{ Radiological Category } \\
\hline & 0 & 1 & 2 & 3 & Totals \\
\hline $20-$ & 0 & 0 & 1 & 0 & 1 \\
\hline 30- & 0 & $\mathbf{0}$ & 2 & 0 & 2 \\
\hline 40 & 3 & 6 & 3 & 4 & 16 \\
\hline $50-$ & 7 & 30 & 21 & 11 & 69 \\
\hline $60-$ & 6 & 35 & 38 & 32 & 111 \\
\hline $70+$ & 2 & 10 & 21 & 6 & 39 \\
\hline Totals & 18 & 81 & 86 & 53 & 238 \\
\hline
\end{tabular}

TABLE 5

COMPARISON OF FIRST AND SECOND READINGS OF NUMBER OF DUST FOCI IN 238 CASES

\begin{tabular}{|c|c|c|c|c|c|c|c|}
\hline \multirow{2}{*}{\multicolumn{2}{|c|}{ Number of Dust Foci }} & \multicolumn{3}{|c|}{ First Reading } & \multirow{2}{*}{ Totals } & & \\
\hline & & Very Sparse & Moderate & Numerous & & & \\
\hline \multirow{3}{*}{ Second Reading } & Very sparse and sparse & 136 & 20 & 0 & \multirow{3}{*}{$\begin{array}{r}156 \\
53 \\
29\end{array}$} & & \\
\hline & Moderate & 5 & 41 & 7 & & & \\
\hline & Numerous & 0 & 3 & 26 & & & \\
\hline \multicolumn{2}{|r|}{ Totals } & 141 & 64 & 33 & 238 & & \\
\hline & & & & \multicolumn{2}{|c|}{ Agreement } & 203 & $85.3 \%$ \\
\hline
\end{tabular}

TABLE 6

COMPARISON OF FIRST AND SECOND READINGS OF NUMBER OF FIBROTIC NODULES IN 238 CASES

\begin{tabular}{|c|c|c|c|c|c|c|c|}
\hline \multirow{2}{*}{\multicolumn{2}{|c|}{ No. of Fibrotic Nodules }} & \multicolumn{3}{|c|}{ First Reading } & \multirow{2}{*}{ Totals } & & \\
\hline & & None or Occasional & Sparse & Moderate & & & \\
\hline \multirow{3}{*}{ Second Reading } & \multirow{3}{*}{$\begin{array}{l}\text { None or occasional } \\
\text { Sparse } \\
\text { Moderate }\end{array}$} & 123 & 9 & 0 & \multirow{3}{*}{$\begin{array}{r}132 \\
89 \\
17\end{array}$} & & \\
\hline & & 27 & 57 & 5 & & & \\
\hline & & 0 & 5 & 12 & & & \\
\hline \multicolumn{2}{|r|}{ Totals } & 150 & 71 & 17 & 238 & & \\
\hline & & & & \multicolumn{2}{|c|}{ Agreement } & 192 & $80 \cdot 7 \%$ \\
\hline
\end{tabular}

TABLE 7

COMPARISON OF FIRST AND SECOND READINGS OF DEGREE OF EMPHYSEMA IN 238 CASES

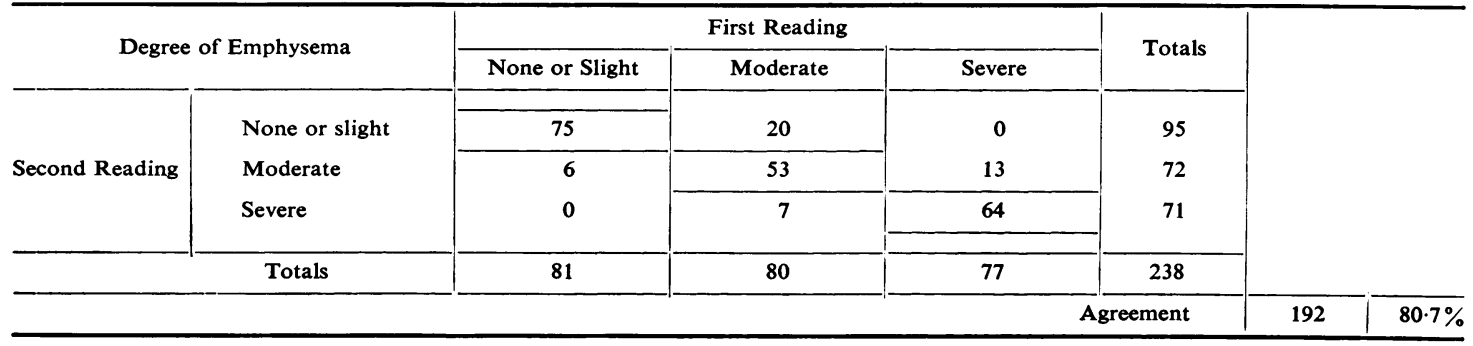


was fair agreement apart from two cases read as numerous in the wet lung and sparse in the large lung section. There was agreement in about $78 \%$ of cases in reading fibrotic nodules (Table 2). A tendency to read a higher proportion with fibrotic nodules was observed in the large lung section. In assessing the degree of emphysema there was less agreement (about 65\%) (Table 3). Moderate and severe emphysema was recorded more frequently in the large lung section than in the wet lung. Of the 80 cases assessed as having moderate emphysema in the large lung sections, approximately equal numbers were put in all three categories when viewing the wet lungs. This suggests that emphysema is easier to see in the lung section than in the wet lung.

As the comparison of the readings of wet lungs and large lung sections for dust foci was fairly good it was decided that the readings of the large lung sections were preferable for radiological correlation, if only because it eliminated the observer bias when reading wet lungs with a prior knowledge of the radiological appearances.

Most of the chest radiographs were taken at the Cardiff Pneumoconiosis Panel where the technique of exposure and development of films is fairly consistent. The radiological classification of pneumoconiosis was based on the International Labour Organization (I.L.O.) Classification (1953), currently followed by the Pneumoconiosis Medical Panels. The films were read by the author without knowledge of the pathology.

The large lung sections and the chest radiographs were re-read by the same observer after an interval of three months, and the first readings of the large lung sections were correlated with the first readings of the radiological category of the comparable lung field.

\section{Results}

Repeatability of Assessments of Radiographs and Lung Sections.-The comparison of first and second readings is shown in Tables $4,5,6$, and 7 . There was agreement in about $80 \%$ of cases in the reading of radiological category, number of fibrotic nodules and emphysema, and in about $85 \%$ in the readings of the total number of dust foci. There was a slight tendency at the second reading to read more as category 1 and fewer as category 2; fewer as moderate and more as sparse dust foci; more with sparse fibrotic nodules; and more cases without emphysema.

Age Incidence.-The age incidence of the 238 cases is shown in Table 8 . Only $19(8 \%)$ were under 50 , and $39(16.4 \%) 70$ or over. The majority were between the ages of 50 and $69 ; 69(29 \%)$ were 50 to 59 , and $111(46.6 \%) 60$ to 69 .
Relation of Radiological Category and Total Dust Foci (Table 9 and Fig. 4).-All cases with category 0 had very sparse or sparse dust foci. With increasing radiological category there was a fall in the proportion of cases with very sparse and sparse dust foci and an increase in the prevalence of moderate and numerous dust foci.

The relation between radiological category and dust foci was somewhat improved if cases with $\mathrm{A}$ shadows were excluded. There was a higher prevalence of sparse dust foci in category 3 cases with A shadows $(38 \%)$ as compared with category 3 without $A$ shadows (13\%). The numbers were small and the difference not statistically significant.

Relation of Radiological Category to Profusion of Fibrotic Nodules.- -None of the cases with category 0 and only $11 \%$ of those with category 1 had fibrotic nodules in the lungs (Table 10 and Fig. 5). In contrast to this, fibrotic nodules were found in about $44 \%$ of cases with category 2 and about $77 \%$ of cases with category 3 . There were no cases with numerous fibrotic nodules. The relation between radiological category and profusion of fibrotic nodules is, therefore, clearer than with total dust foci.

When the cases with A shadows are excluded the percentage of category 2 cases with fibrotic nodules was $28 \cdot 3$ instead of $44 \cdot 2$. The proportion of cases with fibrotic nodules was about three times higher in those with A shadows than in those without A shadows (Table 11).

Relation of Radiological Category and Emphysema.-Table 12 related emphysema to age. There was a rise in the prevalence of emphysema with increasing age up to 69 ; this was most striking between the under 50 and 50 to 59 age groups.

Fig. 6. relates emphysema to radiological category in two age groups (a) below 60 and (b) 60 and over. The prevalence of emphysema was highest in both age groups in those with category 0 and not very closely related to the other radiological categories, although there was a tendency for those with category 1 to have the smallest amount of emphysema.

Table 13 relates emphysema to radiological category and number of dust foci. There were no cases of category 0 with moderate or numerous dust foci, and of the 12 cases of category 1 with moderate or numerous dust foci, five had none or slight emphysema and seven moderate or severe. This finding does not support a widely held belief that emphysema may obscure radiological dust opacities 


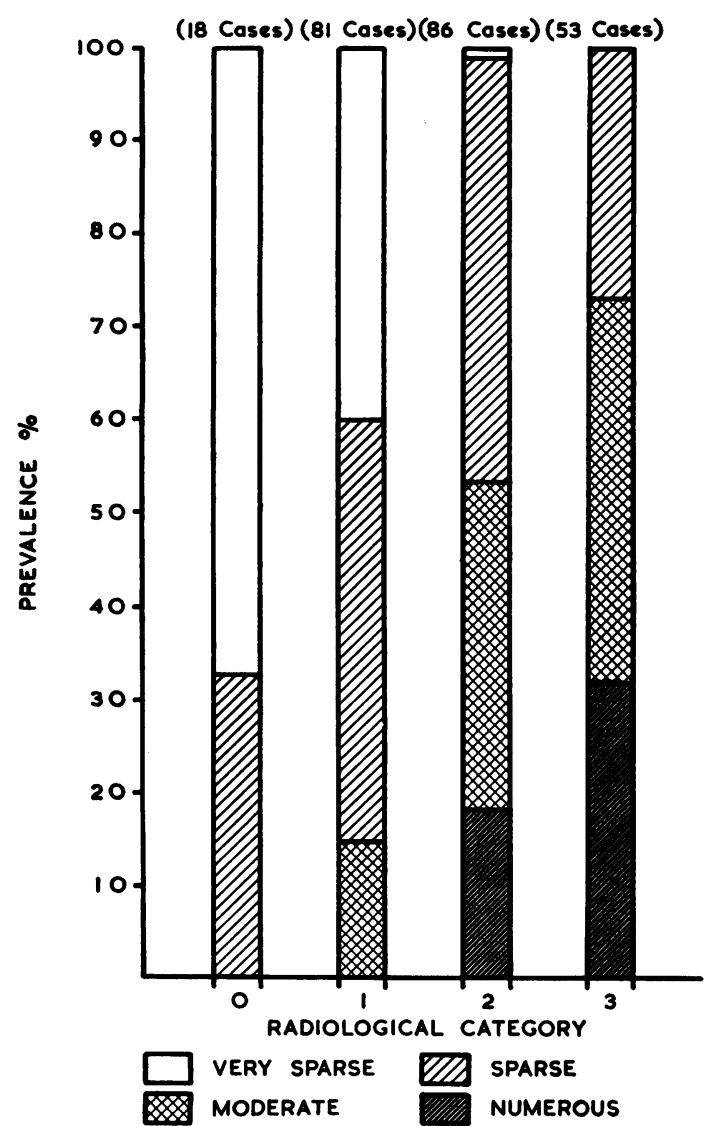

Fig. 4.-The prevalence of sparse, moderate, and numerous dust foci in each radiological category.

and "convert" a category 2 or 3 to 0 or 1 . If this were so there should have been a disproportionate number of cases with moderate and numerous dust foci in categories 0 and 1 with post-mortem evidence of moderate or severe emphysema.

Pathology Associated with Category A Shadows.Table 14 shows that $A$ shadows were accountable

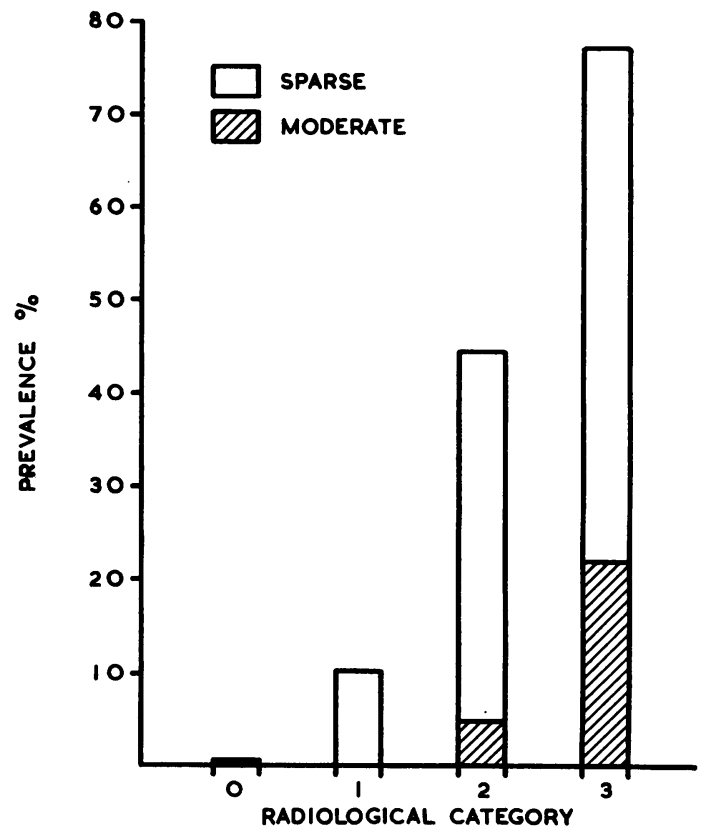

FIG. 5.-The prevalence of fibrotic nodules in each radiological category.

TABLE 10

RELATION OF RADIOLOGICAL CATEGORY TO PROFUSION OF FIBROTIC NODULES IN 238 CASES

\begin{tabular}{|c|c|c|c|c|c|c|c|}
\hline \multirow{3}{*}{$\begin{array}{c}\text { Radiological } \\
\text { Category }\end{array}$} & \multirow{3}{*}{$\begin{array}{l}\text { No. of } \\
\text { Cases }\end{array}$} & \multicolumn{6}{|c|}{ Fibrotic Nodules } \\
\hline & & \multicolumn{2}{|c|}{ Sparse } & \multicolumn{2}{|c|}{ Moderate* } & \multicolumn{2}{|c|}{ Totals } \\
\hline & & No. & $\%$ & No. & $\%$ & No. & $\%$ \\
\hline $\begin{array}{l}0 \\
1 \\
2 \\
3\end{array}$ & $\begin{array}{l}18 \\
81 \\
86 \\
53\end{array}$ & $\begin{array}{r}0 \\
9 \\
33 \\
29\end{array}$ & $\begin{array}{r}0.0 \\
11 \cdot 1 \\
38.4 \\
54.7\end{array}$ & $\begin{array}{r}0 \\
0 \\
5 \\
12\end{array}$ & $\begin{array}{r}0.0 \\
0.0 \\
5.8 \\
22.6\end{array}$ & $\begin{array}{r}0 \\
9 \\
38 \\
41\end{array}$ & $\begin{array}{r}0.0 \\
11.1 \\
44.2 \\
77.3\end{array}$ \\
\hline Totals & 238 & 71 & & 17 & & 88 & $37 \cdot 0$ \\
\hline
\end{tabular}

*There were no cases with numerous fibrotic nodules.

pathologically mainly by progressive massive fibrosis (P.M.F.) $(51 \cdot 4 \%)$, large fibrotic nodules $(25.7 \%)$, and apical scars $(18 \cdot 6 \%)$. Cancer of the lung was the sole

TABLE 9

CORRELATION OF RADIOLOGICAL CATEGORY AND NUMBER OF DUST FOCI IN 238 CASES

\begin{tabular}{|c|c|c|c|c|c|c|c|c|c|}
\hline \multirow{3}{*}{$\begin{array}{c}\text { Radiological } \\
\text { Category }\end{array}$} & \multirow{3}{*}{ No. of Cases } & \multicolumn{8}{|c|}{ Number of Dust Foci } \\
\hline & & \multicolumn{2}{|c|}{ Very Sparse } & \multicolumn{2}{|c|}{ Sparse } & \multicolumn{2}{|c|}{ Moderate } & \multicolumn{2}{|c|}{ Numerous } \\
\hline & & No. & $\%$ & No. & $\%$ & No. & $\%$ & No. & $\%$ \\
\hline $\begin{array}{l}0 \\
1 \\
2 \\
3\end{array}$ & $\begin{array}{l}18 \\
81 \\
86 \\
53\end{array}$ & $\begin{array}{r}12 \\
33 \\
1 \\
0\end{array}$ & $\begin{array}{r}66.7 \\
40.7 \\
1.2 \\
0.0\end{array}$ & $\begin{array}{r}6 \\
36 \\
39 \\
14\end{array}$ & $\begin{array}{l}33 \cdot 3 \\
44 \cdot 5 \\
45 \cdot 3 \\
26 \cdot 4\end{array}$ & $\begin{array}{r}0 \\
12 \\
30 \\
22\end{array}$ & $\begin{array}{r}0.0 \\
14.8 \\
34.9 \\
41.5\end{array}$ & $\begin{array}{r}0 \\
0 \\
16 \\
17\end{array}$ & $\begin{array}{r}0.0 \\
0.0 \\
18.6 \\
32.1\end{array}$ \\
\hline
\end{tabular}


TABLE 11

RELATION OF RADIOLOGICAL CATEGORY TO PROFUSION OF FIBROTIC NODULES IN 70 COAL-WORKERS WITH CATEGORY A SHADOWS

\begin{tabular}{|c|c|c|c|c|c|c|c|}
\hline \multirow{4}{*}{$\begin{array}{c}\text { Radiological } \\
\text { Category }\end{array}$} & \multirow{4}{*}{$\begin{array}{l}\text { No. of } \\
\text { Cases }\end{array}$} & \multicolumn{6}{|c|}{ Character of Dust Foci } \\
\hline & & \multicolumn{6}{|c|}{ Fibrotic } \\
\hline & & \multicolumn{2}{|c|}{ Sparse } & \multicolumn{2}{|c|}{ Moderate } & \multicolumn{2}{|c|}{ Totals } \\
\hline & & No. & $\%$ & No. & $\%$ & No. & $\%$ \\
\hline $\begin{array}{l}1 \\
2 \\
3\end{array}$ & $\begin{array}{r}8 \\
33 \\
29\end{array}$ & $\begin{array}{r}2 \\
20 \\
20\end{array}$ & $\begin{array}{l}25 \cdot 0 \\
60 \cdot 6 \\
69 \cdot 0\end{array}$ & $\begin{array}{l}0 \\
4 \\
4\end{array}$ & $\begin{array}{r}0.0 \\
12.1 \\
13.8\end{array}$ & $\begin{array}{r}2 \\
24 \\
24\end{array}$ & $\begin{array}{l}25 \cdot 0 \\
72 \cdot 7 \\
82 \cdot 8\end{array}$ \\
\hline Totals & 70 & 42 & & 8 & & 50 & $71 \cdot 4$ \\
\hline
\end{tabular}

TABLE 12

EMPHYSEMA RELATED TO AGE IN 238 CASES

\begin{tabular}{|c|c|c|c|c|c|c|c|}
\hline \multirow{3}{*}{$\underset{\text { (years) }}{\text { Age }}$} & \multicolumn{6}{|c|}{ Degree of Emphysema } & \multirow{3}{*}{ Totals } \\
\hline & \multicolumn{2}{|c|}{ None or Slight } & \multicolumn{2}{|c|}{ Moderate } & \multicolumn{2}{|c|}{ Severe } & \\
\hline & No. & $\%$ & No. & $\%$ & No. & $\%$ & \\
\hline $\begin{array}{l}\text { Up to } 49 \\
50- \\
60- \\
70+\end{array}$ & $\begin{array}{l}12 \\
26 \\
31 \\
12\end{array}$ & $\begin{array}{l}63 \cdot 2 \\
37 \cdot 7 \\
27 \cdot 8 \\
30 \cdot 8\end{array}$ & $\begin{array}{r}44 \\
23 \\
40 \\
13\end{array}$ & $\begin{array}{l}21 \cdot 6 \\
33 \cdot 3 \\
36 \cdot 1 \\
33 \cdot 3\end{array}$ & $\begin{array}{r}3 \\
20 \\
40 \\
14\end{array}$ & $\begin{array}{l}15 \cdot 2 \\
29 \cdot 0 \\
36 \cdot 1 \\
35 \cdot 9\end{array}$ & $\begin{array}{r}19 \\
69 \\
111 \\
39\end{array}$ \\
\hline Totals & 81 & & 80 & & 77 & & 238 \\
\hline
\end{tabular}

TABLE 13

EMPHYSEMA RELATED TO RADIOLOGICAL CATEGORY AND NUMBER OF DUST FOCI IN 238 CASES

\begin{tabular}{|c|c|c|c|c|c|c|c|c|c|c|}
\hline \multirow{3}{*}{$\begin{array}{c}\text { No. of } \\
\text { Dust Foci }\end{array}$} & \multirow{3}{*}{ Degree of Emphysema } & \multicolumn{8}{|c|}{ Radiological Category } & \multirow{3}{*}{ Totals } \\
\hline & & \multicolumn{2}{|c|}{0} & \multicolumn{2}{|c|}{1} & \multicolumn{2}{|c|}{2} & \multicolumn{2}{|c|}{3} & \\
\hline & & No. & $\%$ & No. & $\%$ & No. & $\%$ & No. & $\%$ & \\
\hline Sparse & $\begin{array}{l}\text { None or slight } \\
\text { Moderate or severe }\end{array}$ & $\begin{array}{r}4 \\
14 \\
\end{array}$ & $\begin{array}{r}7 \cdot 4 \\
16 \cdot 1\end{array}$ & $\begin{array}{l}32 \\
37\end{array}$ & $\begin{array}{l}59 \cdot 3 \\
42 \cdot 5\end{array}$ & $\begin{array}{l}14 \\
26\end{array}$ & $\begin{array}{l}25 \cdot 9 \\
29 \cdot 9\end{array}$ & $\begin{array}{r}4 \\
10\end{array}$ & $\begin{array}{r}7 \cdot 4 \\
11 \cdot 5\end{array}$ & $\begin{array}{l}54 \\
87\end{array}$ \\
\hline \multirow[t]{2}{*}{$\begin{array}{l}\text { Moderate and } \\
\text { numerous }\end{array}$} & $\begin{array}{l}\text { None or slight } \\
\text { Moderate or severe }\end{array}$ & $\begin{array}{l}\mathbf{0} \\
\mathbf{0}\end{array}$ & $\begin{array}{l}0.0 \\
0.0\end{array}$ & $\begin{array}{l}5 \\
7\end{array}$ & $\begin{array}{l}18 \cdot 5 \\
10 \cdot 0\end{array}$ & 12 & $\begin{array}{l}44 \cdot 4 \\
48 \cdot 6\end{array}$ & $\begin{array}{l}10 \\
29\end{array}$ & $\begin{array}{l}37 \cdot 1 \\
41 \cdot 4\end{array}$ & $\begin{array}{l}27 \\
70\end{array}$ \\
\hline & Totals & 18 & & 81 & & 86 & & 53 & & 238 \\
\hline
\end{tabular}

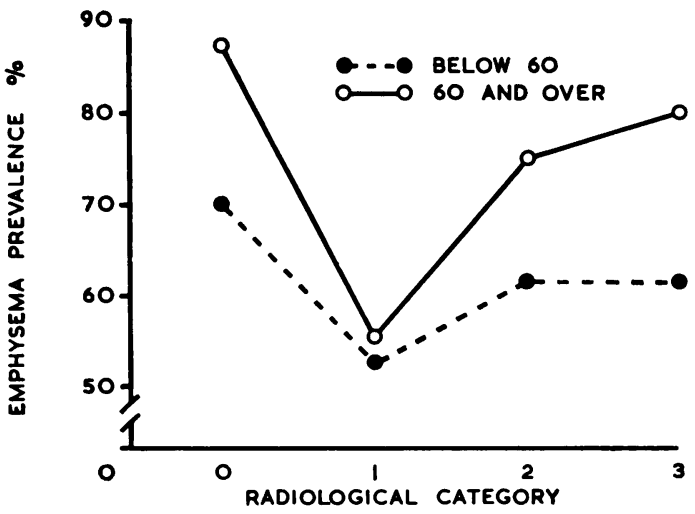

FIG. 6.-The prevalence of moderate and severe emphysema related to radiological category and age.

gross lesion in two cases $(2.9 \%)$ and, in addition, was present in two other cases with P.M.F. Bronchiectasis was considered to be the cause in one case $(1.4 \%)$ and was also associated in one case with P.M.F. Interstitial fibrosis ("cystic" disease) may have contributed to the A shadow in one case with an apical scar.

Apical scarring was the commonest apparent cause for A shadows in category $1(75 \%)$, whereas it caused A shadows in only $9 \%$ of cases in category 2 
error both in reading radiographs and assessing the number and character of dust foci found in the lungs after death? A very close correlation of radiograph readings and post-mortem findings cannot be expected. Nevertheless, the findings of this investigation suggest that there is fairly good correlation between the radiological category of simple pneumoconiosis and the total number of dust foci and proportion of fibrotic nodules found in the lungs at post-mortem examination. The higher the radiological category, the greater is the likelihood that the lungs will show a larger number of dust foci and particularly a greater proportion of fibrotic nodules, and vice versa.

All the 18 cases read as category 0 had very sparse or sparse soft dust foci, and in a high proportion of cases $(66 \%)$ the foci were very sparse. In category 1 the majority $(85 \%)$ had very sparse $(41 \%)$ or sparse dust foci; a small proportion (15\%) had moderate foci. In $89 \%$ of cases the foci were soft, and in $11 \%$ sparse fibrotic nodules were present. As soft dust foci do not show an appreciable degree of collagenous fibrosis histologically, these findings suggest that when an experienced observer reads category 0 or 1 , there will probably be very little simple pneumoconiosis found in the lungs of all cases of category 0 and in most cases with category 1 .

In categories 2 and 3 the proportion of cases with sparse dust foci fell ( $46 \%$ and $26 \%$ respectively) and the proportion of moderate $(35 \%$ and $41 \%$ respectively) and numerous ( $19 \%$ and $32 \%$ respectively) rose. In addition fibrotic nodules were present in $44 \%$ of cases with category 2 and $77 \%$ of cases with category 3 ; in about $6 \%$ of cases with category 2 and $23 \%$ in category 3 the fibrotic nodules were moderate in number.

A comparison of cases with and without A shadows showed no significant difference in the distribution of the total number of dust foci in category 2 but a surprisingly higher prevalence of sparse dust foci in cases of category 3 with $A$ shadows $(38 \%)$ as compared with those without $\mathrm{A}$ shadows $(13 \%)$. This theoretically could be attributed to the possibility that dust had migrated to the P.M.F. lesion. A more likely explanation is that there was a relatively high proportion of category 3 cases with sparse dust foci most of which were fibrotic.

A significant finding in comparing the prevalence of fibrotic nodules in cases with and without A shadows was the very much higher proportion with fibrotic nodules in category 2 with $\mathrm{A}$ shadows $(72.7 \%$ as compared with $28.3 \%$ ). The probable explanation is that both fibrotic nodules and the causes of A shadows-commonly P.M.F. or conglomeration of large fibrotic nodules-have a common aetiological factor. In category 3 cases there was a high proportion of fibrotic nodules in those with and without $\mathrm{A}$ shadows $(82.8 \%$ and $75 \%$ respectively). It is also of interest that more than $50 \%$ of cases with category 3 had A shadows.

Rivers et al. (1960) found that fibrous nodules occur mainly in the lungs which contain most dust although they may also occur in lungs with a low dust content. This suggested to the authors that the nodules are probably not produced by dust alone and they considered infection to be a likely additional factor, particularly tuberculosis (cf., Gough, 1947). Fibrous nodules were found by Rivers in $33 \%$ of his 45 cases. This prevalence of fibrotic nodules is similar to that found in this investigation (37\%). Rivers et al. also found a clear increase in the average weight of total dust with increasing radiological category. This was paralleled in this investigation with the finding that the proportion of cases with moderate and numerous dust foci rose with increasing radiological category.

Rivers et al. concluded that "there is little or no relation between radiological category and the presence of fibrotic nodules". This appears to be in conflict with the findings of the present investigation. It is to be noted, however, that Rivers did find a higher prevalence of fibrotic nodules in categories 2 and $3(40 \%$ and $67 \%$ respectively) as compared with categories 0 and $1(23 \%)$. The difference of opinion is, therefore, one of interpretation of findings rather than actual difference in results. In this investigation it was considered that there was a clearer relation between radiological category and profusion of fibrotic nodules than with the total number of dust foci. These observations suggest that the number of fibrotic nodules probably influences the radiological category more than the total number of soft dust foci. Indeed personal experience has shown that in cases with an indisputable radiological category 3 , the lungs at necropsy not infrequently show only sparse but mainly fibrotic nodules. The findings of this investigation tend to confirm this observation in that in 12 of the 14 cases read as category 3 with sparse dust foci, the lesions were mainly fibrotic. A typical example is shown in Fig. 7. Conversely category 0 may be read in lungs having moderate soft dust foci.

One of the more important reasons for relating emphysema to dust foci and radiological category was to test a current belief that emphysema may obscure radiological dust opacities and thereby "convert" a category 2 or 3 to category 0 or 1 . These findings did not support this contention in that there was not a disproportionate number of cases with moderate and numerous dust foci in categories 0 or 1 when moderate or severe emphysema was present. 


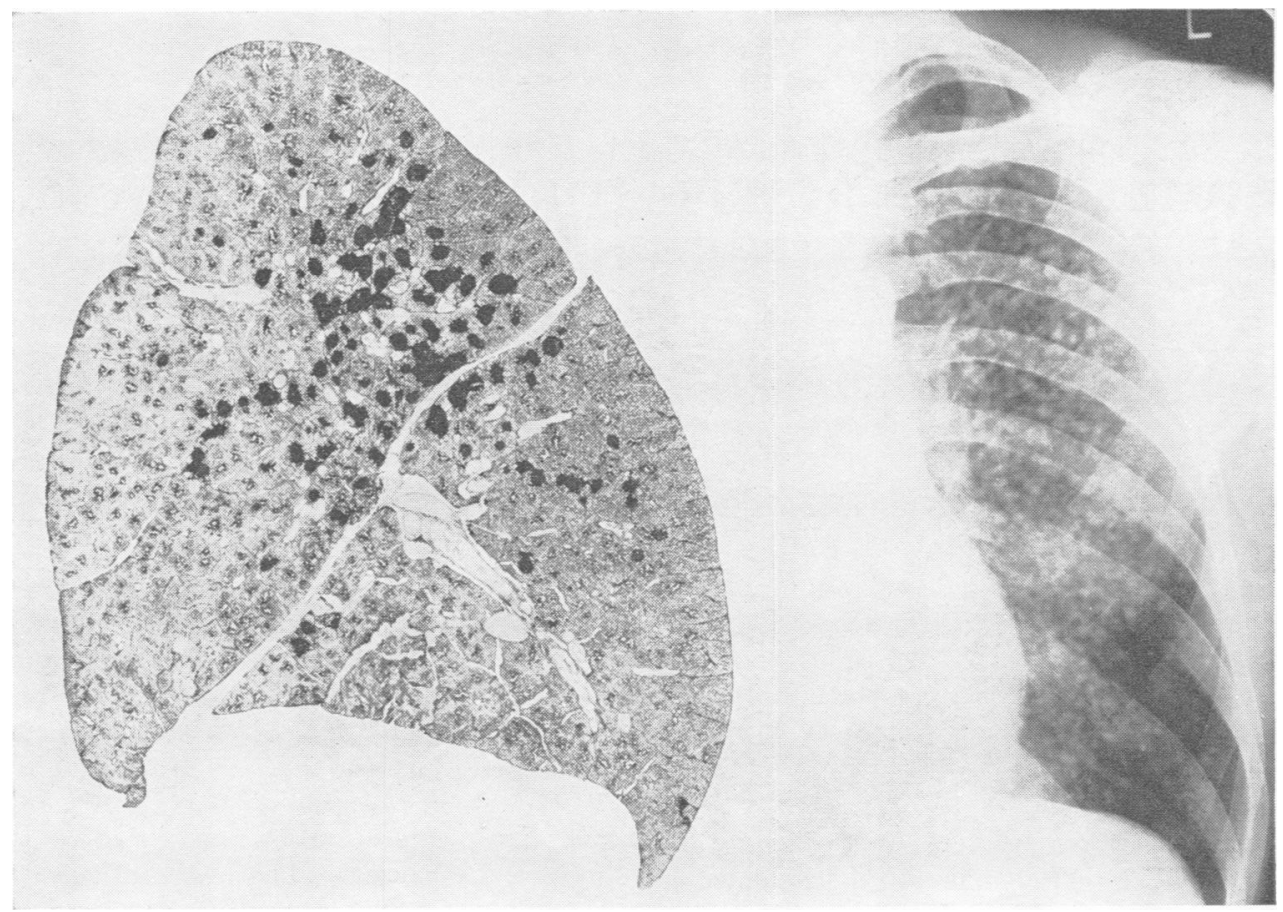

Fig. 7a and b.-Example of large lung section and radiograph of corresponding lung field showing category 3 nodular.

The material used in this investigation may well have had an odd distribution of the prevalence of emphysema. No firm conclusions regarding the relation of emphysema to age, radiological category, and number of dust foci can therefore be drawn.

The commonest causes of A shadows in categories 2 and 3 were P.M.F. and large fibrotic nodules, whereas in category 1 most of the A shadows were due to apical scars. Other rarer causes found were cancer of the lung, bronchiectasis, and "cystic" disease.

I wish to acknowledge my thanks to the Chief Medical Officer, Ministry of Pensions and National Insurance, for permission to publish this paper, and to Professor J. Gough of the Institute of Pathology at the Welsh National School of Medicine who provided the large lung sections. Much valuable advice and criticism was given by Professor A. L. Cochrane and Dr. J. C. Gilson of the Pneumoconiosis Research Unit and Professor J. Gough, and I am further indebted to Dr. J. C. Gilson for the figures drawn and photographed by members of his staff. Dr. Enid Rogers took part in the original investigation and her help and advice are much appreciated.

\section{REFERENCES}

Ciba Guest Symposium (1959). Thorax, 14, 286.
Gough, J. (1947). In Silicosis, Pneumokoniosis and Dust Suppression in Mines (Proc. Conf. London, 1947), p. 7. Institution of Mining Engineers and Institution of Mining and Metallurgy, London.

- James, W. R. L., and Wentworth, J. E. (1949). J. Fac. Radiol. (Lond.), 1, 28

International Labour Organization (1953). Third International Conference of Experts on Pneumoconiosis, Sydney, 1950. Record of Proceedings, 1, 126. Internal Labour Office, Geneva.

Rivers, D., Wise, M. E., King, E. J., and Nagelschmidt, G. (1960). Brit. J. industr. Med., 17, 87 .

Roach, S. A. (1953). ibid., 10, 220. 